\title{
Geoprocessamento aplicado ao zoneamento geoambiental: subsídio à implantação de empreendimentos de geração de energia eólica
}

\author{
Geoprocessing applied to geoenvironmental zoning: subsidy to implementation of wind \\ power generation projects
}

\author{
SANTOS $^{1}$, W. A. A.; ARAUJO, P. C. \\ welson_geo@yahoo.com.br
}

\begin{abstract}
Resumo
Este trabalho traz em seu escopo a utilização de técnicas de geoprocessamento aplicadas em um zoneamento geoambiental, referente a um estudo de caso ocorrente no município de Rio do Fogo, litoral Oriental do Estado do Rio Grande do Norte. Para desenvolver o trabalho ora apresentado, fez-se necessária a utilização e interpretação de imagens de satélites, ortofotocartas, cartas topográficas e outras bases cartográficas para verificação das áreas a serem zoneadas. Além disso, foram realizadas incursões em campo para adquirir informações georreferenciadas dos elementos ambientais representativos como, por exemplo, a verificação das Áreas de Preservação Permanente (APP's), das áreas de reserva legal, dos elementos morfoestruturais, fisiográficos, pedológicos, fitofisionômicos, hidrográficos, dentre outros. As informações das unidades geoambientais adquiridas foram agrupadas e trabalhadas em ambiente SIG, onde foi possível classificar e determinar as áreas prioritárias para o zoneamento, a partir de técnicas de vetorização e de análise espacial. Com o resultado do trabalho foi possível classificar Zonas geoambientais prioritárias para a atividade a ser implantada, denominadas de Zonas de Uso Permitido (ZUP), os locais marginais às áreas sensíveis/vulneráveis foram classificadas como Zonas de Uso Permitido com Restrição (ZUPR) e as áreas com restrições totais, seja do ponto de vista ambiental, técnico ou legal, foram classificadas como Zonas de Uso Não Permitido (ZUNP). A partir desta classificação foi possível gerar um produto cartográfico, com uma escala final de trabalho de 1:28000, capaz de auxiliar no planejamento das formas de uso e ocupação da área estudada, sem causar danos aos elementos geoambientais ora citados, bem como atender a legislação ambiental vigente, garantindo o uso racional do solo.
\end{abstract}

Palavras-chave: Zoneamento Geoambiental, geoprocessamento e Rio do Fogo.

\begin{abstract}
This work brings in its scope the application of geoprocessing techniques used in a geoambiental zoning, referring to a case study occurring in the County of Rio do Fogo, East coast of the State of Rio Grande do Norte. To develop the work presented here, it was necessary to use interpretation of satellite images, orthophotos, topographic maps and others cartographical base for verification of the areas to be zoned. In addition, there were carried out raids in field to acquire georeferenced information of representative environmental elements such as verifying the Permanent Preservation Areas (PPAs), the legal reserve areas, the morphostructural elements, physiographic, pedological, phytophysiognomic, hydrographic, among others. The informations of the geoenvironmental units were grouped and worked in a GIS environment, where it was possible to classify and determine the priority areas for zoning, from vectorization techniques and spatial analysis. As a result of this study was possible to classify priority geoenvironmental zones for the activity to be implemented, called Zonas de Uso Permitido (ZUP), marginal places to sensitive / vulnerable areas were classified as Zonas de Uso Permitido com Restrição (ZUPR) and areas with total restrictions, whether from an environmental, technical or legal point of view, were classified as Zonas de Uso Não Permitido (ZUNP). From this classification it was possible to generate a cartographic product with a working final scale of $1: 28000$, able to assist in the occupation of the desired area without damage to geoenvironmental elements cited, as well as comply with the environmental regulations, ensuring the rational use of the areas.
\end{abstract}

Keywords: Keywords: geoenvironmental zoning, geoprocessing, County of Rio do Fogo.

\section{INTRODUÇÃO}

As fontes de energias renováveis no Estado do Rio Grande do Norte já são uma realidade concreta. Sua matriz mais é expressiva é, até o momento, a energia eólica. As atividades ligadas a

\footnotetext{
${ }^{1}$ Welson Aialon Alcaniz dos Santos, setor de geoprocessamento, CRN-Bio Consultorias Integradas, Natal-RN, Brasil

${ }^{2}$ Paulo César de Araujo, Departamento de geografia, UFRN, RN, Brasil
} 
essa fonte de energia alternativa, iniciada no ano de 2009 nesse Estado, é fruto da forte demanda energética no país que, associada ao forte investimento nacional e internacional, amplia ainda mais a busca por regiões promissoras em termos de produtividade e capacidade de geração de energia. Para ratificar tal assertiva, segundo o Centro de Estratégias em Recursos Naturais e Energia CERNE (2014), o Rio Grande do Norte é um dos cinco estados brasileiros com maior potencial de geração de energia elétrica utilizando a força dos ventos, e poderá atingir sete gigawatts $(7 \mathrm{GW})$ de capacidade geradora eólica instalada ao final do corrente ano, 2016, o que equivale a 50\% da produção atual da maior hidrelétrica brasileira, a usina de Itaipu, em Foz do Iguaçu no Paraná.

Diante desse cenário promissor, a busca por regiões com alto potencial para implantação, geração e distribuição de atividades ligadas ao setor eólico se torna uma das grandes demandas dentro da perspectiva atual. Essa prerrogativa não se deve a falta de áreas com grande incidência de vento, ou por falta de projetos, mas, sobretudo, pela burocracia em se licenciar empreendimentos desta seara em determinadas regiões.

Além dos fatores supracitados, a fragilidade ambiental de algumas áreas especuladas, bem como o desconhecimento de alternativas técnicas e locacionais que busquem identificar as melhores áreas para a indústria dos ventos se traduz em um entrave aos empreendedores nacionais e, principalmente, internacionais.

Atualmente, o Estado do Rio Grande do Norte passa por um processo de "interiorização" das demandas nos projetos de energias renováveis, estendendo-se ao Agreste e ao Sertão Central. Entretanto, é na região litorânea onde ocorrem as maiores especulações de propriedades, pois, além das condições naturais serem propícias à atividade, o fator locacional é crucial para tal demanda.

Diante dessa perspectiva, no ano de 2014 surge a oportunidade de realizar um estudo prévio para analisar a viabilidade ambiental de uma determinada área, localizada no município de Rio do Fogo no litoral oriental do Estado do Rio Grande do Norte (figura 01), a fim de proceder-se a instalação de um empreendimento eólico. Para tanto, a busca por técnicas que subsidiasse a verificação dos melhores locais para se implantar a atividade foi crucial, uma vez que o empreendimento se insere em um município de grande relevância ambiental e econômica. 


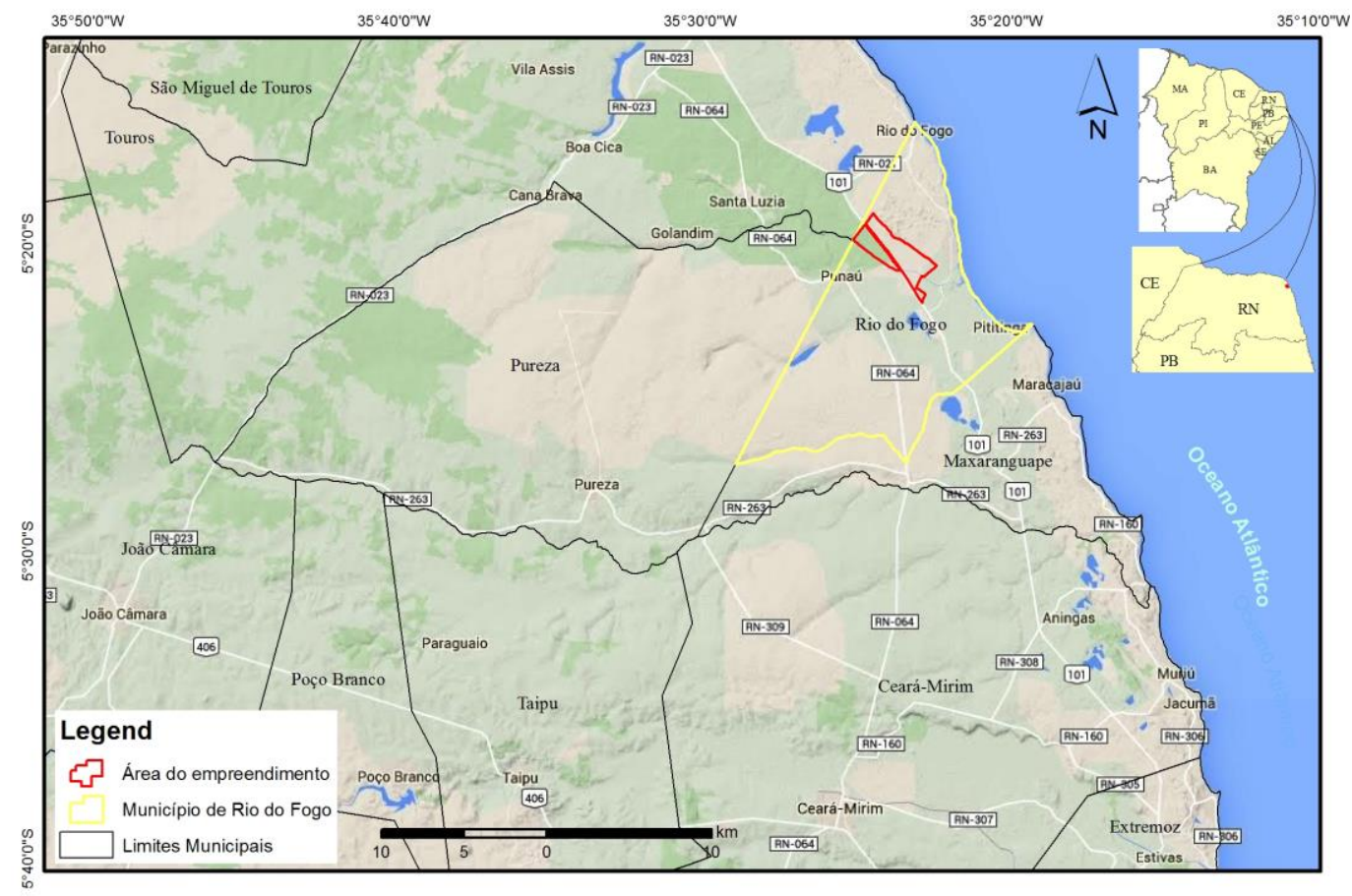

Figura 1 - Localização da área de estudo no município de Rio do Fogo, Rio Grande do Norte. Fonte - O autor.

A partir das informações previamente mencionadas, se recorreu ao uso do geoprocessamento como ferramenta de análise técnica para verificar quais as melhores áreas para a instalação do empreendimento. Além disso, tomou-se como base a definição teórica o zoneamento geoambiental, ao qual este artigo tecerá as considerações na sequência.

\section{METODOLOGIA}

O escopo metodológico aplicado na elaboração do estudo proposto seguiu duas linhas de pesquisa; a primeira, relativa ao entendimento de zoneamento geoambiental, capaz de estruturar o desenvolvimento teórico do projeto; a segunda refere-se ao uso do geoprocessamento como instrumento técnico e de análise, cujo objetivo fundamental foi o de definir as zonas a serem utilizadas pelo projeto, fazendo com que o empreendimento pudesse se adequar aos parâmetros legais, ambientais e técnicos.

Para confirmar as informações adquiridas através dos produtos dos sensores remotos que também foram utilizados na pesquisa, foi necessário realizar incursões em campo com o objetivo de coletar, verificar, comparar e analisar os dados obtidos nas interpretações advindas do imageamento com a realidade observada in loco. Foram realizadas quatro (4) campanhas de campo entre os meses de setembro de 2014 a janeiro de 2015. 
Ressalta-se que a área escolhida para a realização do Zoneamento advém de uma demanda empírica, por parte de empreendedores do setor eólico e que, por motivos éticos e de sigilo industrial, não será feira menção à empresa solicitante do estudo.

\section{$\underline{\text { Síntese sobre a concepção teórica do zoneamento (geo)ambiental }}$}

Em seu sentido etimológico, zonear significa separar, dividir em zonas. Porém, a partir de determinada concepção epistemológica, o termo zoneamento pode adquirir diferentes formas de abordagem e, consequentemente, pontos de vista distintos. Na definição de SILVA (2003, pag. 268), este destaca que:

“[...] zoneamento consiste na repartição do território municipal à vista da descrição da terra e do uso do solo, definindo, no primeiro caso, a qualificação do solo em urbano, de expansão urbana, urbanizável e rural; e no segundo dividindo o território do município em zonas de uso."

O entendimento do autor supracitado parte de uma premissa de zoneamento engendrado no parcelamento do solo de um município, de maneira genérica. Já para ANTUNES (2005, p. 44-45), há uma visão mais ampla do termo zoneamento. Ele considera que:

“[...] zoneamento é uma atividade que ordena o território e molda-o para um determinado padrão de desenvolvimento e ocupação. Ele tem origem tipicamente urbana, muito embora, nos dias atuais, tenha se expandido para área agrícola, econômica, ecológica, marítima e até mesmo aérea."

Partindo para uma visão mais sistêmica acerca do assunto, Milaré (2004) destaca que o zoneamento ambiental pode ser definido como o resultado de estudos conduzidos para o conhecimento sistematizado de características, fragilidades e potencialidades do meio, a partir de aspectos ambientais escolhidos em espaço geográfico delimitado. O zoneamento ambiental é apresentado na forma de representação cartográfica de áreas com características homogêneas. Essa representação é resultante da interação e interpretação de cartas temáticas (mapas com a representação de determinado aspecto ambiental), elaborados a partir de um processo metodológico.

No tocante a um dos objetos teóricos desse artigo, o zoneamento geoambiental, de acordo com Santos (2004) e Cestaro et. al (2010), existem vários tipos de zoneamentos; alguns previstos pela legislação brasileira (como o agroecológico, ambiental e ecológico-econômico) e outros, não. Estes têm caráter mais acadêmico e técnico; por exemplo, o geoambiental, climático e edafoclimático. Segundo Stefani (2003), o zoneamento geoambiental é o resultado da evolução dos 
conhecimentos a respeito das coberturas de alteração intempérica e suas relações com as rochas subjacentes, associado com informações geológicas, pedológicas, fisiográficas e morfoestruturais para fins de estudos geoambientais. O zoneamento geoambiental é uma parte do processo de planejamento de uso da terra, com a definição de áreas texturalmente homogêneas, segundo suas características naturais e avaliadas em função de suas potencialidades e limitações, com o propósito de determinar suas necessidades de manejo ou conservação e a sua tolerância às Intervenções do homem.

Para compreender o cerne dessa pesquisa, Ohara (1995) esclarece que o zoneamento geoambiental deve ter como meta o fornecimento de subsídios técnicos para orientar e elucidar a tomada de decisões na implementação de alternativas de desenvolvimento regional, compatíveis com a sustentabilidade e vulnerabilidade dos sistemas ambientais.

Em acordo com as afirmações postas acima, tratou-se, portanto, o zoneamento da área em questão como geoambiental, por entender que tal terminologia adequa-se ao objetivo deste trabalho e ao seu enquadramento teórico-metodológico.

Foram utilizados como referências geoambientais na pesquisa os seguintes elementos, que por sua vez subsidiaram a implantação do zoneamento que será apresentado ao longo deste artigo, a saber:

- $\quad$ Elementos morfoestruturais;

- $\quad$ Elementos fisiográficos;

- Características pedológicas;

- $\quad$ Recursos hídricos;

- $\quad$ Fitofisionomia local;

$\underline{\text { Geoprocessamento aplicado ao zoneamento geoambiental }}$

Antes de esclarecer as aplicações práticas do geoprocessamento no âmbito do zoneamento geoambiental, deve-se elencar qual a função do mesmo no contexto científico e metodológico. Em linhas gerais, CÂMARA et. al. (2001), destaca que o termo Geoprocessamento denota a disciplina do conhecimento que utiliza técnicas matemáticas e computacionais para o tratamento da informação geográfica e que vem influenciando de maneira crescente as áreas de Cartografia, Análise de Recursos Naturais, Transportes, Comunicações, Energia e Planejamento Urbano e Regional. Ainda nessa perspectiva, o autor reitera que em um país de dimensão continental como o Brasil, com uma grande carência de informações adequadas para a tomada de decisões sobre os 
problemas urbanos, rurais e ambientais, o Geoprocessamento apresenta um enorme potencial, principalmente se baseado em tecnologias de custo relativamente baixo, em que o conhecimento seja adquirido localmente.

De acordo com a abrangência do termo geoprocessamento e da diversidade de aplicações que o mesmo possui, este artigo enfoca a aplicação de técnicas e procedimentos inerentes ao mesmo, como é o caso do sensoriamento remoto, do Sistema de Informação Geográfica (SIG) e a cartografia como elementos norteadores à condução metodológica da qual este artigo tecerá comentários.

Após o entendimento teórico sobre o conceito de zoneamento foi possível aplicar as técnicas inerentes ao geoprocessamento na elaboração do zoneamento geoambiental. A seguir será demonstrada, de forma cronológica, a execução deste zoneamento até sua fase final, onde foi apresentado o mapa das áreas prioritárias para a instalação do empreendimento eólico proposto.

\section{$\underline{\text { Procedimentos técnicos e operacionais }}$}

Como base para o procedimento técnico-operacional desenvolvido nesta pesquisa, foram utilizadas imagens do local a partir de diferentes sensores remotos, como forma de verificar todas as condições geoambientais do terreno, em diferentes período e estações do ano, para subsidiar, também, as análises na fase de pré-campo e, principalmente, na etapa de pós-campo.

O primeiro produto de sensoriamento remoto utilizado no levantamento preliminar da área foram as ortofotocartas do programa PRODETUR (SETUR/SIN/IDEMA, 2006), com escala de 1:25000 (Figura 02), das quais foram extraídas as curvas de nível de mesma escala que auxiliaram a pesquisa. A partir da utilização das ortofotocartas foi possível identificar elementos ambientais mais complexos como, por exemplo, a delimitação das drenagens e da vegetação devido à qualidade do imageamento e da escala do produto em questão. Associada as ortofotocartas, foram agregadas à pesquisa imagens do aerolevantamento realizado pelo Instituto de Desenvolvimento Sustentável e Meio Ambiente do RN, IDEMA, cujo sobrevoo possibilitou a interpretação de diversos elementos da região em apreço (Figura 03), e foi possível nortear a configuração preliminar das zonas geoambientais da área do empreendimento. 


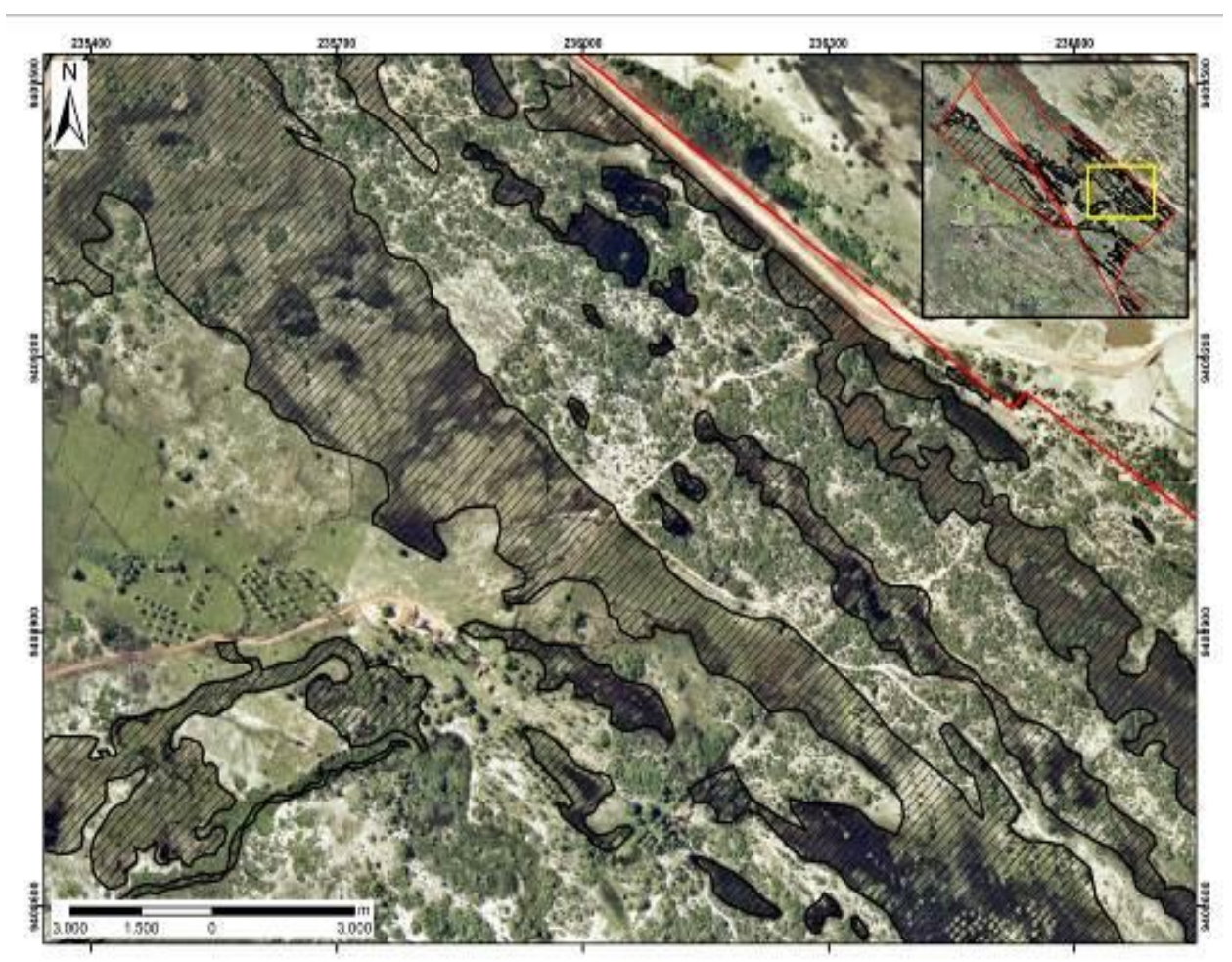

Figura 02 - Ortofotocarta, em detalhe, destacando um dos elementos geoambientais (superfícies alagadas) extraído a partir da interpretação do imageamento. Fonte - PRODETUR/SETUR, 2006 (Adaptado pelo autor).

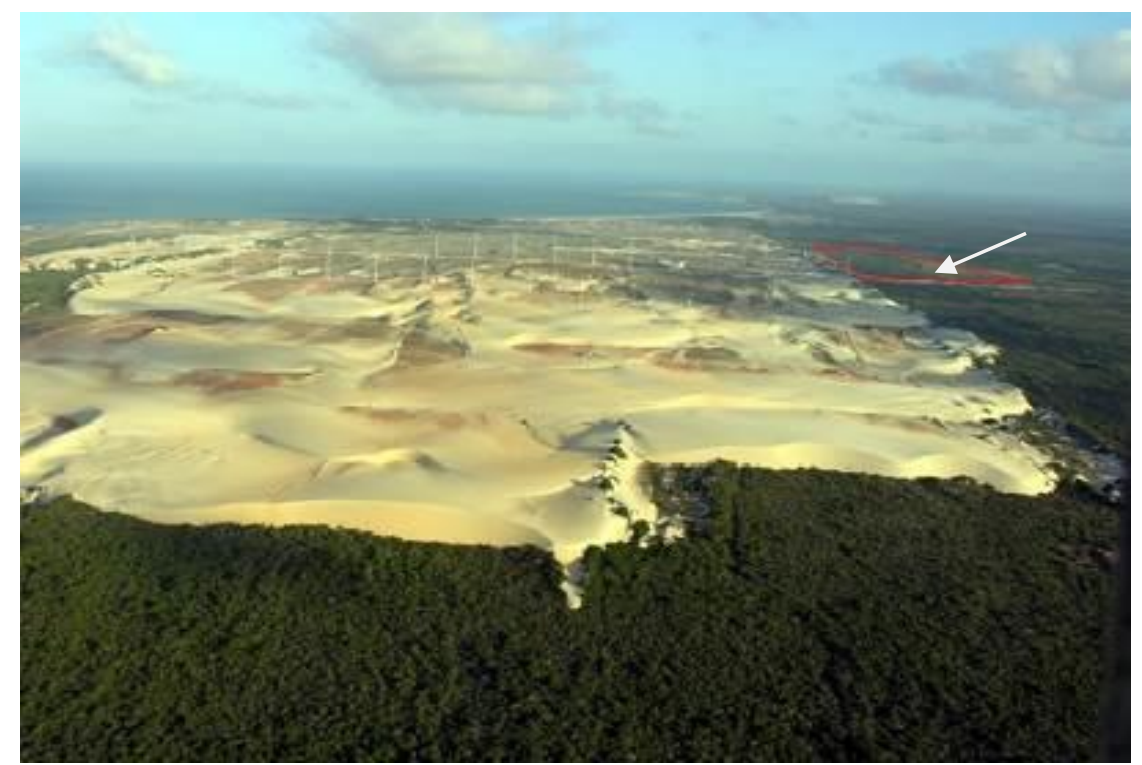

Figura 03 - Parcela da área pleiteada para a instalação da atividade de energia eólica, destacada em vermelho, a Leste/Sudeste. Fonte - IDEMA, 2010.

De posse do conjunto de dados do imageamento da área obtidos a partir do sensoriamento remoto, foram realizadas quatro incursões de campo entre os meses de setembro de 2014 a janeiro de 2015 (Figura 04), com o objetivo de coletar, verificar, comparar e analisar os elementos geoambientais da área, a partir das informações previamente observadas pelos sensores remotos 
acima destacados, como também de melhorar acurácia de elementos até então difíceis de serem representados por informações secundárias.

As informações foram coletadas por uma equipe multidisciplinar de profissionais como, por exemplo, geógrafo, geólogo, químico, engenheiro agrônomo, biólogo/botânico, técnico em geoprocessamento, etc.

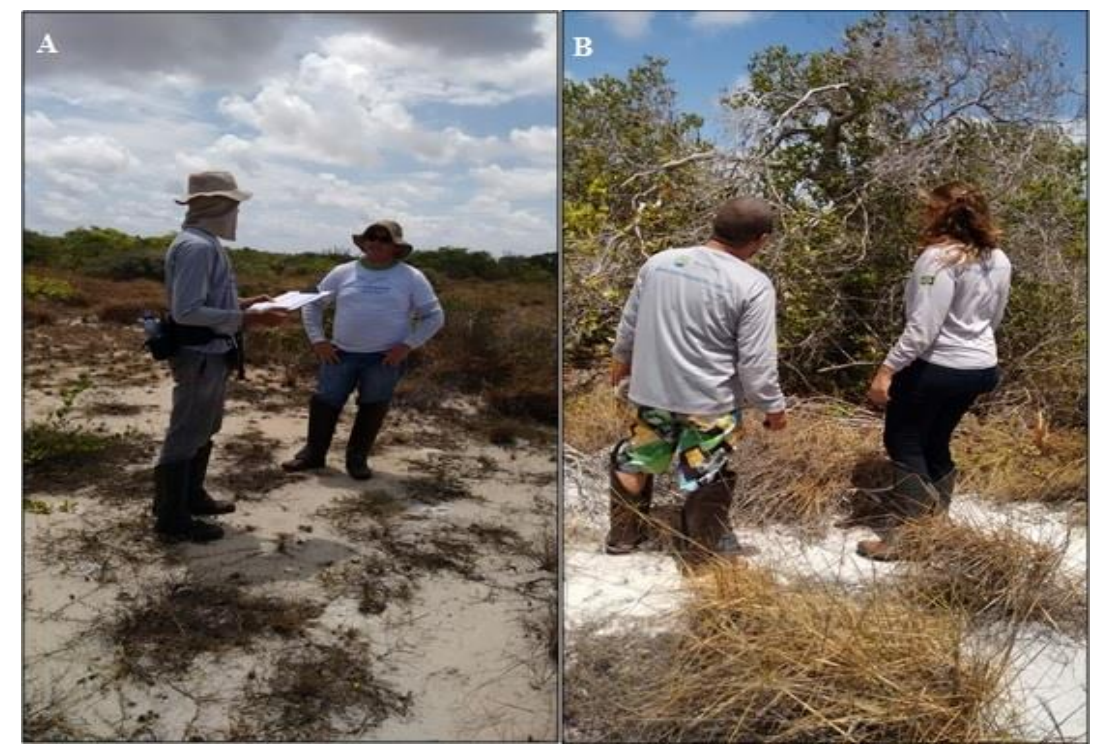

Figura 04 - Trabalho de campo realizado com o objetivo de coletar, verificar, comparar e analisar os elementos geoambientais da área, com relação às informações obtidas pelos produtos de sensoriamento remoto. Em A analisa-se as condições morfoestruturais e pedológicas da área; em B verifica-se as características fitogeográficas. Fonte - CRNBio, 2014.

\section{RESULTADOS E DISCUSSÃO}

\section{$\underline{\text { Verificação das zonas geoambientais a partir de sensores remotos }}$}

Diante da dificuldade em se avaliar toda a área do empreendimento devido ao tamanho e a complexidade do ambiente em que a mesmo se insere, a utilização do sensoriamento remoto se fez fundamental ao resultado da pesquisa, como pôde ser demonstrado acima.

O levantamento de dados por produtos secundários, como é o caso de imagens de satélite e ortofotos, podem apresentar imprecisões ou falsa representatividade com o objeto real. Por tal razão, o cruzamento dessas informações com os dados obtidos em campo se fez crucial diante da pesquisa ora apresentada. Nesse contexto, a definição e o agrupamento dos diversos dados obtidos em campo foram organizados e sistematizados para facilitar a interpretação e, posteriormente, realizado o mapeamento geoambiental do local.

Com a obtenção das imagens georreferenciadas e ortorretificadas e atribuindo, também, ao conhecimento dá área após as incursões de campo, foi possível gerar o modelo vetorial de todos os 
elementos geoambientais anteriormente descritos culminando, assim, na elaboração de um banco de dados, trabalhados em um ambiente de Sistema de Informação Geográfica, SIG, conforme mostrado na sequência.

\section{Definição e agrupamento das zonas geoambientais em ambiente SIG}

A partir da análise dos produtos de sensoriamento remoto previamente demonstrado e, concomitantemente a isso, o levantamento das informações geoambientais em campo, estabeleceuse a sistematização das seguintes unidades geoambientais em ambiente SIG, de acordo com a tabela que se segue.

Tabela 01 - Elementos ambientais analisados em campo e nos produtos de SR, utilizados para definir as unidades geoambientais. Fonte $-\mathrm{O}$ autor.

\begin{tabular}{cc}
\hline Unidades geoambientais & Zonas Geoambientais \\
\hline Tabuleiros interiores, & \\
Depósitos eólicos continentais & Zona de Uso Permitido - ZUP \\
estabilizados; & \\
Áreas antropizadas. & \\
Superfícies alagadas; & \\
Cursos d'água; & Zona de Uso Não Permitido - \\
Restinga; & ZUNP \\
Mata ciliar; & \\
Áreas de Preservação & \\
Permanente e; & Zona de Uso Permitido com \\
Áreas de Reserva Legal & Restrição - ZUPR \\
Restinga antropizada; & \\
Vegetação de Tabuleiro e; & \\
Campos de várzea; &
\end{tabular}

A opção em agrupar as unidades geoambientais estabelecidas para o zoneamento de acordo a viabilidade do projeto e, acima de tudo, consoante à restrição legal de cada uma, foi essencialmente importante para avaliar as condições ambientais do local. O agrupamento dessas variáveis geoambientais foi executado em ambiente SIG, a partir da criação de um Banco de Dados Geográfico (BDGeo) contendo todos os elementos antepostos. Os modelos de dados existentes para SIG estão relacionados com as diferentes formas de percepção da realidade que podem ser empregadas. Estes modelos de dados podem ser divididos segundo duas visões: visão de campo e visão de objetos. No caso da pesquisa que se apresenta a melhor opção para agregar os elementos geoambientais sobre o espaço foi a aplicação do sistema de banco de dados misto, definido entre a visão de campo e a visão de objetos (Quadro 01). Na visão de campo, a realidade foi modelada por variáveis que possuem uma distribuição contínua no espaço, como, por exemplo, a geologia, a 
pedologia e o relevo local. Na visão de objeto, através de infraestruturas como é o caso de estradas, rodovias, etc. (FILHO et al.,1996).

Posterior à criação do banco de dados contendo as informações elencadas, utilizou-se a ferramenta de análise espacial Merge (Unir/fundir), cujo objetivo foi o de agregar as unidades geoambientais a partir de suas características em uma tabela de acordo com seus atributos, classificando-as de acordo com a viabilidade ou restrição de uso da área.

Quadro 01 - Exemplo da estruturação do Banco de Dados Geográfico (BDGeo) desenvolvido para agrupar as unidades geoambientais da pesquisa. Fonte - $\mathrm{O}$ autor.

\begin{tabular}{|l|r|r|l|l|l|}
\hline \multicolumn{1}{|c|}{ DATUM } & BUFF DIST & ORIG FID & \multicolumn{1}{c|}{ area } & \multicolumn{1}{|c|}{ Unidade Geoambiental } & SIGLA \\
\hline SIRGAS 2000 UTM ZONA 25 S & 0 & 0 & 40,772 ha & Depositos eolicos estabilizados & DEE \\
\hline SIRGAS 2000 UTM ZONA 25 S & 0 & 0 & 4,611 ha & Mata ciliar & MC \\
\hline SIRGAS 2000 UTM ZONA 25 S & 0 & 0 & 30,005 ha & Restinga & RES \\
\hline SIRGAS 2000 UTM ZONA 25 S & 0 & 0 & 32,401 ha & Depositos eolicos estabilizados & DEE \\
\hline SIRGAS 2000 UTM ZONA 25 S & 0 & 0 & 3,670 ha & Tabuleiro interior + Veget & TAB e VEG \\
\hline SIRGAS 2000 UTM ZONA 25 S & 0 & 0 & 19,083 ha & Tabuleiro interior + Veget & TAB e VEG \\
\hline SIRGAS 2000 UTM ZONA 25 S & 0 & 0 & 118,199 ha & Depositos eolicos estabilizados & DEE \\
\hline SIRGAS 2000 UTM ZONA 25 S & 50 & 0 & 3,642 ha & APP & APP \\
\hline SIRGAS 2000 UTM ZONA 25 S & 50 & 1 & 16,935 ha & APP & APP \\
\hline SIRGAS 2000 UTM ZONA 25 S & 50 & 2 & 18,613 ha & APP & APP \\
\hline SIRGAS 2000 UTM ZONA 25 S & 50 & 3 & 13,540 ha & Restinga & RES \\
\hline SIRGAS 2000 UTM ZONA 25 S & 50 & 4 & 267,066 ha & Campos de varzea & CV \\
\hline SIRGAS 2000 UTM ZONA 25 S & 0 & 0 & 19,706 ha & Reserva Legal & RL \\
\hline SIRGAS 2000 UTM ZONA 25 S & 0 & 0 & 24,126 ha & Reserva Legal & RL \\
\hline SIRGAS 2000 UTM ZONA 25 S & 0 & 0 & 44,542 ha & Reserva Legal & RL \\
\hline SIRGAS 2000 UTM ZONA 25 S & 0 & 0 & 45,365 ha & Reserva Legal & RL \\
\hline SIRGAS 2000 UTM ZONA 25 S & 0 & 0 & 262,588 ha & Superficies Alagáveis & SA \\
\hline
\end{tabular}

A classificação final das Zonas Geoambientais, de acordo com os critérios acima destacados, ficou assim estabelecida:

Tabela 2 - Unidades geoambientais definidas x Zonas Geoambientais. Fonte - O autor.

\begin{tabular}{cc}
\hline Unidades geoambientais & Zonas Geoambientais \\
\hline Tabuleiros interiores, & \\
Depósitos eólicos continentais & \\
estabilizados; & Zona de Uso Permitido - ZUP \\
Áreas antropizadas. & \\
Superficies alagadas; & \\
Cursos d'água; & \\
Restinga; & Zona de Uso Não Permitido - \\
Mata ciliar; & ZUNP \\
Áreas de Preservação & \\
Permanente e; & \\
Áreas de Reserva Legal & \\
Restinga antropizada; & Zona de Uso Permitido com \\
Vegetaçăo de Tabuleiro e; & Restrição - ZUPR \\
Campos de várzea; &
\end{tabular}

A utilização das siglas acima apresentadas associadas, sobretudo, as características coropléticas das zonas geoambientais, informam, também, as unidades/feições ambientais verificadas para zoneamento. 


\section{$\underline{\text { Cartografia aplicada ao zoneamento geoambiental }}$}

A aplicação e a representação cartográfica ao zoneamento ora proposto é concebido como o produto final deste artigo. Devido à importância que os elementos cartográficos exercem para essa pesquisa, a preocupação pela definição da melhor visualização dos elementos geoambientais foi um dos principais norteadores na confecção do mapa final, uma vez que para representar tantas variáveis ambientais é preciso destacar visualmente o objetivo proposto, de maneira objetiva e de fácil análise.

A confecção de um mapa requer, entre outras coisas, a seleção das características a serem incluídas no mapa, a classificação dessas características em grupos, a simplificação para representação, a ampliação de certas características para que possam ser representadas e a escolha de símbolos para representar as diferentes classes, FILHO et al. (1996).

Nesse contexto, foi possível a representação das zonas ambientais através de técnicas cartográficas aplicando um sistema coroplético de fácil identificação e análise. A busca por um padrão de cartografia temática se fez oportuno para a geração do zoneamento, uma vez que as unidades geoambientais se sobrepõe sobre o espaço geográfico.

Com o resultado do trabalho foi possível representar as Zonas Geoambientais prioritárias para a atividade a serem implantadas, denominadas de Zonas de Uso Permitido (ZUP), com coloração verde; os locais marginais às áreas mais vulneráveis foram classificados como Zonas de Uso Permitido com Restrição (ZUPR), de coloração Amarela; e as áreas com restrições totais, seja do ponto de vista ambiental, técnico ou legal, foram classificadas como Zonas de Uso Não Permitido (ZUNP), em coloração vermelha. A partir desta classificação foi possível gerar um produto cartográfico, com uma escala final de trabalho de 1:28.000, apresentado a seguir. 


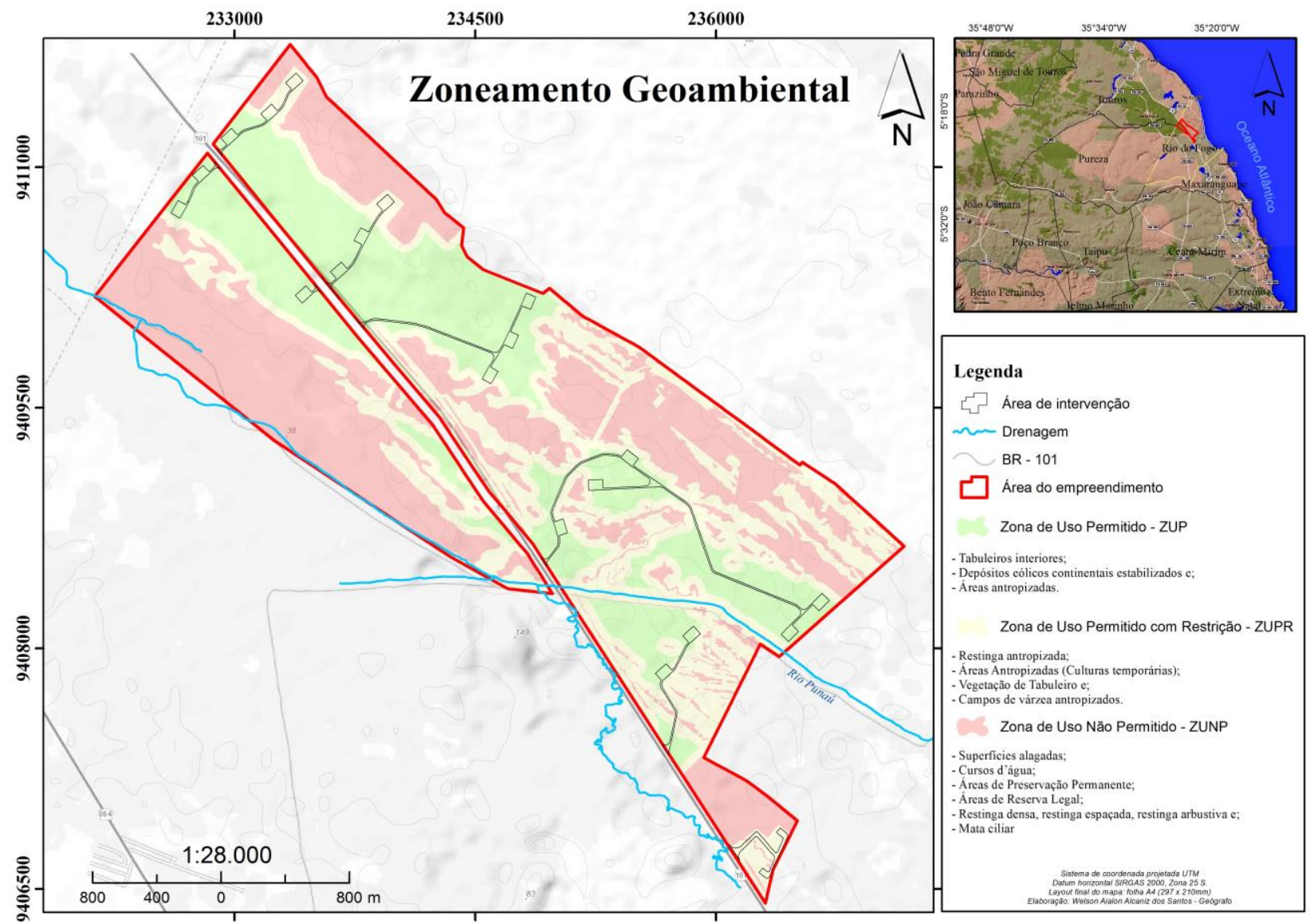

Figura 05 - Zoneamento Geoambiental da área pleiteada para o empreendimento de energia eólica, município de Rio

\section{CONSIDERAÇÕES FINAIS} do Fogo, RN. Fonte - O autor, 2015.

O artigo ora apresentado destacou, de maneira objetiva e prática, a aplicação do geoprocessamento como técnica essencial à análise espacial, desenvolvendo uma estreita relação entre este e a concepção teórica do zoneamento geoambiental, abordando, também, a efetivação de elementos cartográficos, do Sistema de Informação geográfica (SIG), do sensoriamento remoto e da pesquisa direta de campo, na composição da metodologia empregada neste trabalho.

Embora as pesquisas científicas direcionadas a aplicação das técnicas de geoprocessamento aliadas aos Zoneamentos Geoambientais ainda serem escassas, os resultados apresentados por este artigo respondem a uma demanda recorrente dentro do processo de licenciamento ambiental para empreendimentos de média e alta complexidade, como é o caso das atividades de energias renováveis. Espera-se que, com o avanço das atividades de energia eólica e solar no Estado, a procura por técnicas que facilitem a interpretação de áreas com alta sensibilidade ambiental, bem como para diminuir custos excessivos no pleito do licenciamento, o desenvolvimento de pesquisas relativas ao Zoneamento Geoambiental sejam mais expressivas e que a utilização do geoprocessamento se faça presente como um aliado para todos os setores interessados, sejam eles da iniciativa pública (na figura dos órgãos licenciadores), da iniciativa privada (na figura dos 
empreendedores e pesquisadores), reforçando, nesse sentido, a capacidade de preservação do meio ambiente e de ecossistemas vulneráveis.

\section{REFERÊNCIAS}

ANTUNES, Paulo de Bessa. Política Nacional do Meio Ambiente PNMA: Comentários à Lei 6.938, de 31 de agosto de 1981. Rio de Janeiro: Lumen Juris, 2005.

CÂMARA, Gilberto. DAVIS, Clodoveu. MONTEIRO, Antônio Miguel Vieira. Organizadores. Introdução à Ciência da Geoinformação. São José dos Campos, INPE, 2001. on-line, 2a . edição, revista e ampliada. Acesso: http://www.dpi.inpe.br/gilberto/livro/introd/

Centro de Estratégias em Recursos Naturais e Energia - CERNE. A indústria dos ventos e o Estado do Rio Grande do Norte. Idealização e Autoria: Jean-Paul Prates, 2014. Data de acesso: 20/08/2015.

CESTARO, Luiz Antonio. LIMA, Flávia Jorge de. CONSIDERAÇõeS SOBRE ZONEAMENTOS COMO INSTRUMENTOS DE GESTÃO DO TERRITÓRIO. Revista brasileira de geografia física, 2010. Universidade Federal de Pernambuco. ISSN - 0104-5490.

FILHO, Jugurta Lisboa. IOCHPE, Cirano. Introdução a Sistemas de Informações Geográficas com Ênfase em Banco de Dados. Apostila editada nos seguintes eventos: $10^{\mathrm{a}}$ Escuela de Ciencias Informáticas, Departamento de Computación, Universidad de Buenos Aires, Argentina, 22 a 27 de julho de 1996. XV JAI - Jornada de Atualização em Informática, XVI Congresso da SBC, Recife-PE, 4 a 9 de agosto de 1996.

MILARÉ, Édis. Direito do ambiente: doutrina, jurisprudência, glossário. $3^{a}$ ed. revisada, atualizada e ampliada. São Paulo: Revista dos tribunais, 2004.

OHARA, T. Zoneamento geoambiental da região do alto-médio Paraíba do Sul (SP) com sensoriamento remoto. Tese de Doutoramento. Rio Claro, IGCE/UNESP.1995. 235 p.

SANTOS, R. F. dos. Planejamento Ambiental: teoria e prática. São Paulo: Oficina de Textos, 2004.

SETUR/SIN/IDEMA. SECRETARIA DE ESTADO DO TURISMO DO RIO GRANDE DO NORTE. SECRETARIA DE ESTADO DE INFRA-ESTRUTURA.PRODETUR/IDEMA. Polo Costa das Dunas. Brasília: Topocart Topografia, Engenharia e Aerolevantamentos Ltda. Arquivos em formato digital (vetorial e matricial). Escala 1:25.000. 2006.

SILVA, José Afonso da. Direito ambiental constitucional. $4^{a}$ ed. revisada e atualizada. São Paulo: Malheiros, 2003.

STEFANI, Fausto Luis. ZONEAMENTO GEOAMBIENTAL DA REGIÃO DE CASA BRANCA/SP. Dissertação de Mestrado em Sensoriamento Remoto. Instituto Nacional de Pesquisas Espaciais - INPE, São José dos Campos, 2000.

\section{AGRADECIMENTOS}

Agradecemos o apoio dos departamentos de pós-graduação em oceanografia e limnologia da UFRN e ao departamento de geografia da UFRN. Agradecemos em especial à CRN-Bio consultorias integradas pelos dados disponibilizados e pelo trabalho de campo.

Recebido em: 14/08/2016

Aceito para publicação em: 01/10/2016 